\title{
International roaming in the EU: historic overview, challenges, opportunities and solutions
}

Marlies Van der Wee, Jonathan Spruytte, Mieke De Regt, Sofie Verbrugge ${ }^{1}$

As technology evolves and globalization continues, the need for reasonably priced roaming services has never been higher. In 2007, the European Commission (EC) introduced a first set of regulatory decisions to cap the maximal additional roaming fee end users have to pay for calling. In the years after, additional price caps have been introduced for SMS and data, initially only for end users, in a later stage also for the inter-operator tariff. The final step, named Roaming Like at Home (RLAH), will start to take effect in June 2017, from then end users will pay the same price (for voice, SMS and data) when roaming like in their domestic country.

The effect of RLAH on the business case of each mobile operator is hard to predict, as the different national markets are extremely heterogeneous and operators face large discrepancies in terms of roaming usage due to different traveling patterns and various other reasons that cannot be harmonized (geography, economics, working force, usage history, etc.). Furthermore, competition in the telecom market will no longer be a purely national matter, as the decision to abolish roaming tariffs will expose operators to other players within Europe.

This paper aims at providing insights in the effect of RLAH for both the end user as well as the mobile operators. Following a literature survey approach, including a detailed overview of the roaming regulation process from 2007 up to now, the paper discusses possible effects the RLAH initiative might trigger, going from lower wholesale prices for mobile operators to higher retail prices for end users. Additionally, as the European Commission strives for a single European market, this paper presents a number of technical solutions (carrier portability, software-based SIMs, cross-border IMSI) that pose an alternative for roaming and explains how these may impact cross-border competition both positively and negatively. The solutions are assessed against two axes: (1) generating the best possible outcome for the end customers (in all countries), and (2) ensuring the best level playing field for (virtual) mobile operators in Europe, which will of course involve tradeoffs on different levels.

Keywords - roaming, policy, Europe, MVNO

\footnotetext{
${ }^{1}$ The views and opinions expressed in this article are those of the authors and do not necessarily reflect the official policy or position of any agency.
} 


\section{Introduction and motivation}

The globalization of the world is changing the way we live. The increased integration between European countries as well as the increasing prosperity of the EU citizens has led to an increase in intra-European travel [1]. People have always had an interest in using mobile services while travelling, and the smartphone revolution - always being connected - has only increased this trend. When using mobile services in a foreign country, your local provider - the Domestic Service Provider (DSP) - cannot rely on its own network for voice or data transmissions (unless it is a cross-country operator (such as Vodafone or Deutsche Telekom), owning networks in multiple countries). Because of this, users have no other choice than to use the network of an operator in the visited country - a Foreign Service Provider (FSP). When a user is using a FSP, a process referred to as international roaming, the DSP will be charged a fee (the roaming fee) by the FSP as the FSP is offering connectivity to the end user on behalf of the DSP. The DSP of course will recuperate this cost on the retail level by charging the end user a retail roaming charge ${ }^{2}$.

In the past, retail pricing for roaming services was significantly higher than retail pricing for local services, resulting in travelers being reluctant to use international roaming. Users were afraid of receiving big bills (causing "bill shocks") when using roaming services. This resulted in most of the travelers deciding to switch off their mobile handset during the whole trip, switch off the data roaming capabilities of their mobile phone or smartphone, or only connect to the Internet using public or private Wi-Fi access points [2]. This impacted both DSPs and FSPs, as additional revenues were hampered due to a more limited usage of mobile services when in a roaming situation. Furthermore, as Neelie Kroes (European Commissioner for the Digital Agenda) indicated: "It's not just a fight between holiday-makers and telecoms companies. Millions of businesses face extra costs because of roaming, (...) Roaming makes no sense in a (European) single market - it's economic madness" [3]. In other words, the European roaming problem affects not only people who travel for pleasure but also businesses whose employees travel around Europe, which translates into significant roaming bills.

To counter these problems caused by high mobile roaming retail prices, the European Commission (EC) started to regulate the international wholesale and retail roaming markets within the European Economic Area (EEA). Their purpose was, and still is, to reduce retail roaming charges to zero (i.e. lowering roaming pricing to the same level as local retail pricing). Hence, every citizen of a country in the EEA will be able use their mobile services in every other country of the EEA at the same price as in their own domestic country. At first, this approach seems to yield nothing but benefits; however, there are a number of threats and consequences that may arise as a direct result of RLAH: Will pricing differences arise between countries where a lot of travellers travel to in comparison to countries where a lot of travellers travel from? Will virtual operators (MVNOs - Mobile Virtual Network Operators) face a competitive disadvantage in the national market as they will only have an outflow of roaming wholesale cost, which can no longer be recuperated? Are the benefits for international providers significant or rather disruptive to good market functioning? In this paper, we discuss a number of these (unwanted) effects and how these might affect the end users.

\footnotetext{
${ }^{2}$ Please note the difference between wholesale costs, wholesale charges and wholesale caps. Wholesale costs denote the actual cost for the operator (FSP) to allow roamers' traffic on its network. The wholesale cap is the maximum fee this FSP may charge the DSP, and has been set by Europe Commission. The wholesale charge, ideally, lies in between the wholesale cost and wholesale cap, and is the actual fee the DSP pays to the FSP, based on inter-operator negotiations. The wholesale charge is therefore frequently referred to as interoperator tariff. The retail roaming charge is the fee an end user pays the DSP when roaming.
} 
This paper starts by giving a general overview of the evolution of roaming in the EU. Section 3 then details the economic and business impact for customers and telecom operators. Based on both the technological possibilities and economic implications, a number of possible strategies and solutions for the future are discussed in section 4 . Finally, section 5 concludes the paper.

\section{The evolution of roaming in the EU}

Early in 1999, when complaints about excessive rates for international roaming began, the EC started to be concerned about the problem of roaming and launched a sector investigation, which led to the conclusion that there was a market failure in the International Roaming Services (IRS) wholesale markets. This market failure existed because of a lack of competition among operators, due to the absence of incentives for the operators to make this competition happen. Therefore, the EC decided to include this market ("national wholesale market for international roaming services on public mobile networks") in the 2003 EC recommendation on relevant markets, making it become subject to ex-ante regulation. This regulatory framework supports that ex-ante regulatory obligations should only be imposed where there is no effective competition, and supports imposing ex-ante obligations on operators designated as having significant market power [4]. The national regulatory authorities (NRAs) were obliged to define and assess the conditions of effective competition. However, as each NRA is only responsible for its own territory, regulation was fragmented and could not help tackling the lack of competition EU-wide [5].

As NRAs were not successful in tackling high roaming costs, and pressure from Member States grew accordingly, the EC imposed a roaming regulation for the whole EEA in 2007 (directly applicable in all Member States) based on the following key facts:

(1) both wholesale and retail prices were not justified by the underlying costs (international roaming charges were 3-5 times higher than the costs [6]),

(2) the lack of retail price transparency (most of consumers were not aware of the high charges for incoming calls),

(3) both issues could not be solved using the existing regulatory tools [7].

This 2007 Roaming Regulation (Roaming I) introduced caps for voice wholesale and retail prices (for both incoming and outgoing calls), forcing the operators to use this so-called Eurotariff by default. Other pricing tariffs were however still allowed if they would lead to lower retail prices.

In June 2009, the Roaming Regulation I was reviewed. The EC decided to continue on its price caps strategy for voice, lowering them in order to reduce the gap between wholesale and retail prices (Roaming II). Additionally, SMS and data service prices were regulated. For SMS, both wholesale and retail caps were presented (for both incoming and outgoing), whereas for data services, the regulation remained limited to wholesale caps (because the market for data services was then rather young, and hence its estimated evolution was not completely clear). Finally, a feature to protect consumers from "bill shocks" was introduced: if a certain billing amount for data services is reached ( $€ 50$ excl. VAT), the operator is obliged to notify its user. At this point, users are allowed to decide to spend more money on data services or stop the service.

Following the reasoning that wholesale prices are related to the respective cost for the operators, BEREC assessed the wholesale roaming market and conducted an estimation of the wholesale roaming costs [8] to better estimate the pricing regulation. As the report pointed out that costs had decreased over the years, it was decided to further reduce roaming fees. As a result, the 2012 Roaming Regulation (Roaming III, covering the period from 2012 to 2022), continued lowering the 
caps. It reduced wholesale caps significantly in 2014 and added caps for retail data services prices for the first time. Table 1 presents the evolution of the regulated wholesale and retail prices of voice calls, SMS and data services for the three roaming regulations induced by the EC.

Table 1: Evolution of wholesale and retail price caps (eurocents, excl. VAT) for voice calls, SMS and data services

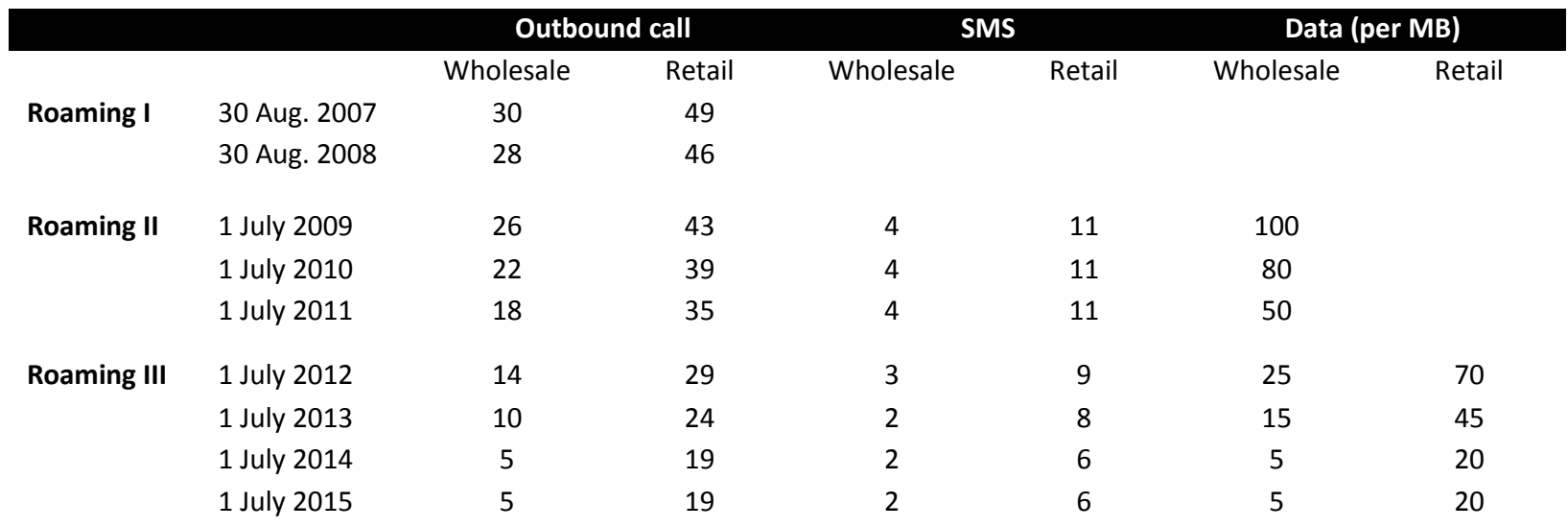

In September 2013, the EC first introduced their new strategic action "Roam Like at Home (RLAH)" [9], being the most ambitious plan in 26 years of telecoms market reformations. RLAH should allow end users to use their mobile phone when abroad in the EEA without any surcharges. This indicates that all underlying costs, transit costs, fixed and operational costs related to roaming would become completely invisible to the end user.

In April 2014, the EU Parliament voted to finally abolish retail roaming surcharges, in order to allow customers to "Roam Like at Home". From that point onwards, legislators were charged with working out the details of how this could be made possible, reaching an agreement across all the EU-member states [10].

Though the abolition of roaming pricing in Europe is beneficial for every European traveler, for most operators (apart from larger cross-country operators such as Telefónica or Vodafone), this may currently not be sustainable. The impact on the business case for the different operators is not comparable, on the one hand due to the differences between MNO and MVNO, but on the other hand due to the significant differences between the member states, such as the levels of retail tariffs, the costs, and travelling and consumption patterns. With RLAH, the number of consumers using roaming services will have a significant increase that will mean less revenues and bigger wholesale bills for the operators. In addition, they will have to face the increasing demands on their networks.

In October 2015, the EC stated that the reduction-to-zero strategy is aimed to be finished by June 2017. This means that, after more than 10 years of regulations and prices caps, European roaming fees (on the retail level) will be abolished entirely and Europeans will be able to travel and use their mobile services like at home. In order to completely build up to the point where no additional roaming fees are allowed, an intermediate regulation has been introduced as represented in Table 2 . Whereas the three initial roaming actions stated absolute limits for retail prices (Table 1), these last steps have lowered the retail caps to the sum of the domestic price plus an additional surcharge, equal to the wholesale prices for calls, SMS and data. 
Table 2: Intermediate step of the retail price caps (eurocents, excl. VAT) for voice calls, SMS and data services, leading up to the introduction of Roaming Like At Home [11]

\begin{tabular}{clccccccc}
\hline & & \multicolumn{2}{c}{ Outbound call } & \multicolumn{2}{c}{ SMS } & \multicolumn{2}{c}{ Data (per MB) } \\
& & Wholesale & Retail & Wholesale & Retail & Wholesale & Retail \\
RLAH & 30 April 2016 & 5 & Domestic & 2 & Domestic & 5 & Domestic \\
$\begin{array}{c}\text { intermediate } \\
\text { step }\end{array}$ & until & 14 June 2017 & & +5 & & +2 & & +5 \\
\end{tabular}

As a final step, before the introduction of RLAH will come into effect, the European Commission recently proposed new wholesale rates that will, if accepted, be in effect from June 2017 [12], based on a review of the wholesale roaming market and a cost model. The proposed rates have to be approved by the Member States and the EU Parliament in the next months, ultimately before February 2017.

It can be concluded that roaming in Europe has gone through multiple processes of regulation since 2007, first with imposing wholesale and retail price caps for calls, then for SMS and finally for data. The next step is to abolish the roaming retail charges, which may permit users to roam like at home. However, there are several aspects that the EC has to clarify, especially for the operators, as there are doubts about how they are going to sustain this transition. This paper aims at listing the threats and opportunities, as well as proposing solutions or strategies for the future.

\section{Economic and business impact of cutting roaming fees}

The prospects of abolishing roaming pricing by 2017 is of course beneficial for end customers, but also clearly impacts the business case for all telecom operators, both MNOs and MVNOs (Mobile (Virtual) Network Operators). Operators will no longer be able to cover their own roaming costs by customer's fees on the retail level and will now only be compensated with the same price they charge their customers for offering domestic services within their own network. The absolute impact will however depend on the type of operator and its geographical coverage and location. This section describes this impact shortly and proposes remedies operators can take to counter it or at least safeguard their business case.

\subsection{Impact for telecom operators}

As mentioned above, the main impact of reducing roaming fees to zero, is that the operators cannot charge their customers directly for using mobile services abroad. There are however large differences in between different types of operators. For MNOs (owning their own network), the distinction needs to be made between geographical location and geographical coverage. For MVNOs (not having an own physical network), the situation has to assessed differently. Besides, the costs of providing connectivity (and therefore RLAH) vary significantly across the EU, underpinned by significant differences in, e.g., spectrum costs, labour and property costs, and coverage obligations and costs due to different geographies, which are major drivers of the cost of providing mobile services [13].

\subsubsection{Impact of geographical location}

The impact of cutting roaming fees is significantly different depending on the country the operator is active in, mainly because of the different amounts of incoming and outgoing roaming travellers and the demand for roaming services. For example, Scandinavian countries such as Sweden experience traffic imbalances, having much more outgoing roaming traffic because people in those countries 
travel a lot to the south of Europe. As a direct result, wholesale costs for these operators are rather bulky. By cutting the retail roaming fees, they will no longer be able to recuperate these costs. As a result, there is a risk these mobile operators will increase domestic prices in order to compensate for the wholesale losses (this is the so called 'waterbed effect'). Countries with a lot of incoming traffic from tourists on the other hand, such as Spain and Greece, have an incentive to keep wholesale charges high as operators need to invest in capacity to allow the additional roaming traffic on their networks [13]. In Eastern European countries, domestic tariffs are cheap and the outgoing traffic is limited because people do not travel too much (95\% of the people in Romania and Bulgaria have not been abroad in the last 5 years [2]).

On the other hand, Günther H. Oettinger (European Commissioner for Digital Economy and Society) stated: "The Commission does not believe that there is a risk of a rise in mobile phone prices as a result of the progressive elimination of roaming. The elimination of roaming surcharges is a long standing goal, for which the agreement was reached by the European Parliament and the Council on the Commission's proposal. The agreement recognizes that the abolition of the roaming surcharges should be achieved in a sustainable way and that the wholesale roaming market needs to evolve, either through market forces or regulatory intervention, to a level that makes the end of retail surcharges sustainable throughout the EU. The agreement also envisages development of fair use limit, and provides additional safeguards for the domestic operators" [14].

Hence, in order to mitigate any waterbed effect caused by roamers, the European Commission will propose a Fair Use Limit that operators can apply once RLAH is into effect (Fair Use Limits set a maximum amount of roaming per customer per time period, see section 3.2.2 for a detailed explanation). Additionally, in the specific case when an operator is not able to recover its overall costs of providing roaming services, this operator can be exempted from the obligation to provide RLAH and will be able to apply a surcharge for roaming services, in order to ensure its business case. The details of this exemption mechanism, as well as the details of the Fair Use Limit, will be determined by the European Commission and published by 15 December 2016.

\subsubsection{Impact of geographical coverage}

One specific category of telecom operators in Europe are those whose coverage region extends beyond national borders, the so-called cross-country operators. Table 3 shows an overview of the international operators active in Europe, as well as the number of countries they serve. Operators who are part of a cross-country group, will be able to get cheap wholesale roaming prices by using their own network facilities [6]. They can steer their roaming traffic, internalize their costs and are hence not faced with the burden of wholesale roaming fees [13].

Table 3: International operators active in the EU [15]

\begin{tabular}{|l|c|}
\hline MNO & Number of countries \\
\hline Vodafone & 15 \\
\hline Deutsche Telekom & 11 \\
\hline Orange, TeliaSonera & 8 \\
\hline Hutchison, Tele2, Telefonica & 6 \\
\hline Telenor & 5 \\
\hline TelekomAustria & 4 \\
\hline KPN & 3 \\
\hline Belgacom, BITE, Elisa, Iliad, PPF & 2 \\
\hline
\end{tabular}




\subsubsection{Impact for MVNOs}

Finally, there are MVNOs, those who do not own a physical network. MVNOs resell capacity that they rent from an MNO and hence challenge the incumbent operators, though often take up only a small part of the domestic market. In a roaming situation, MVNOs incur in costs when their customers are travelling, but they do not have wholesale incomes as they cannot host any roamers on their network, since they do not own a network. They experience absolute traffic imbalances and they do not have the bargaining power to negotiate wholesale roaming fees which are lower than the ceiling caps imposed by the European Commission. For MVNOs, the risk of the waterbed effect is even more pertinent than for MNOs with high outbound roaming traffic. Hence, for MVNOs it is crucial that the EC sets lower wholesale caps in order to mitigate an outflow of wholesale transaction which cannot be recuperated on the retail level, in order to assure a positive business case of these smaller players. When this issue is not tackled accordingly, the introduction of RLAH might have a negative side effect on the level of competition within the national market [16].

In June 2016 [12] the European Commission has proposed a significant reduction of the wholesale caps for data, voice and SMS. In the coming months, the Member States still have to approve on the proposed rates. MVNOs are pleading for lower caps, whereas Southern countries are advocates of higher caps. The debate is complex, as nobody does exactly know what is the 'sweet spot' for operators in order to offer RLAH on a sustainable basis. As BEREC (the umbrella organization of all telecom regulators in the EEA) has pointed out, the situation is made more complex by differences between operators and between travel patterns of consumers within individual Member States. In the next months, legislators at the EU-level have the difficult task to make trade-offs between the policy objectives of promoting greater use of roaming services, protecting competition, protecting investment and, most importantly, protecting European consumers [13].

\subsection{How to reduce or counter this impact?}

As described above, a number of operators across Europe will experience a significant influence from cutting the roaming fees. The revenues for some providers will be reduced, obliging them to look for new possibilities to recover their costs. They can raise prices of other (domestic) mobile services (section 3.2.1), but this may have a negative impact on their customer base. To prevent abuse of RLAH by "permanent roaming", Fair Use Limits can protect the providers (section 3.2.2). Alternatively, they might be able to lower their costs by negotiating new Inter-Operator (wholesale) pricing (section 3.2.3). This section shortly describes these methods the operators could implement to fully counter or at least reduce the impact of cut roaming fees.

\subsubsection{Raise domestic prices}

As already mentioned above, a first possibility is to raise the domestic prices, also known as the waterbed effect. When the retail roaming prices decrease on one side, the domestic prices will increase on the other side [6]. This situation is unfavorable as everyone, also the customers who never roam, will need to pay higher domestic prices to cover the losses made by the customers who do roam. This means that only the people who roam frequently will benefit from this situation. Research by BEREC has proven that the average amount of citizens in the EEA who travel at least once a year is $35 \%$ and the average days abroad within the EEA is 5.7 days [13]. Looking at these numbers, we can say that a large group of customers (mostly blue collar workers and elderly people) will need to pay more so that a small group of customers who frequently roam will pay less (in 
general business people). This is an undesired outcome. How much domestic prices should increase to cover for the losses will strongly depend on the country in which the mobile operator is active, as discussed in section 3.1.1. Additionally, operators in competitive markets (e.g. the UK or France) might be reluctant to increase their domestic prices, protecting their market share. Hence, the degree of possibility to raise domestic prices also depends on the competitive environment within a country.

\subsubsection{Fair use limits}

When customers do not need to pay roaming surcharges, they might be tempted to purchase a SIMcard of a foreign operator that offers lower pricing than any domestic operator, hence enjoy cheaper pricing and use roaming also when being at home. This scenario, known as permanent roaming, will lead to higher wholesale roaming charges for the foreign operator, leading again to the waterbed effect. On a larger scale, permanent roaming will also detriment the telecom sector in those countries with - on average - more expensive mobile prices. Fair Use Limits (FULs) are a way to counter this problem: they set a maximum amount of roaming per customer per time period. When the customer exceeds this limit, he will need to pay a surcharge. FULs can be implemented in different ways. The limit can be set to a specific amount of roaming per day, week, month or even per year. When the FUL is exceeded, a fair surcharge per usage or daily/weekly flat fee could be levied. There will be a need of some caps for the FUL. Currently, the EC is working on a draft how the FUL may look like, which should be adopted by the EC by the 15 December 2016. At the time of writing, no details about the FUL were published yet [17].

Instead of sticking with the domestic operator and accepting the charges for usage beyond the FUL, an end user could switch over to Local Breakout (LBO). LBO is a decoupling ${ }^{3}$ mechanism with minimal configuration, which allows a user to buy a roaming bundle from an FSP. All data (LBO is not applicable to voice and SMS) is directly charged from the prepaid bundle. As calling (VOIP) and texting (e.g. WhatsApp) is increasingly done via the Internet, heavy users could still benefit from an LBO package with much more volume than the volume limit of the FUL.

\subsubsection{Decrease wholesale roaming prices}

The third and final remedy discussed here focuses on the cost side: the best solution for operators might be to reduce wholesale charges, the price a DSP needs to pay to the FSP when a DSP's customer is roaming on the FSP's network. In the past, these wholesale prices were high, allowing the FSP to take significant margins on his own cost [6]. Though local (national) competition has decreased domestic tariffs, the lack of competition on the international roaming market has left the wholesale roaming prices unchanged. As until recently, these high wholesale prices could be charged directly to the end customers as part of their retail roaming fees, there was no pressing need for sharp reduction of these wholesale charges.

As part of their policy, the EC has set wholesale caps for roaming. Finding a correct level of these caps is not easy. Setting the caps too low (below-cost), will put pressure on the FSP providing roaming to customers of foreign providers (again risking a raise in domestic pricing of this FSP) [13].

\footnotetext{
${ }^{3}$ The term decoupling denotes splitting the roaming and domestic services provided to a single subscriber [5]. In its roaming regulation of 2012 (Roaming III), Europe included two methods for technical interaction between operators: the decoupling methods of single International Mobile Subscriber Identity (single IMSI) and Local Breakout (LBO). In its most recent Regulation of 2015, the European Commission abolished the obligation for operators to implement the single-IMSI method, it was not commercially viable because of high negotiation and technical implementation cost. The LBO-obligation is maintained, anticipating a larger demand for data roaming services in the future.
} 
If these caps are too high, they will not be very effective. Hence, the best option is to set the wholesale caps just above the cost of the FSP, so there is a small margin that can be used to improve the quality of the visited network and the costs for the DSP are not too high. As mentioned in section 2, the European Commission has proposed new wholesale rates which will, if accepted, take effect from June 2017 [12] .

These wholesale roaming price caps are maximum limits, but providers still can negotiate interoperator prices. As indicated in section 3.1, MNOs have much more bargaining power than MVNOs, this also applies to discussing wholesale rates with FSPs. There are two reasons for this: (1) as MVNOs have no network of their own, they cannot offer an FSP access to their network and (2) they usually have smaller client bases, hence lower outgoing traffic volumes, which decreases leveraging power.

\section{Solutions and strategies for the future}

This final section takes the economic impact described in the previous section as input to discuss potential solutions and strategies for the future of mobile networks in Europe.

\subsection{Carrier portability and Apple SIM}

Technical regulation in the form of number portability enabling users to switch (domestic) network providers is legally guaranteed in the European regulatory framework for fixed networks as well as for mobile networks. A proper extension of number portability to the concept of carrier portability can provide a solution for stimulating competition on the markets for international roaming from the customers' perspective [18]. In order to implement carrier portability, customers should have the right to switch mobile communications providers at any time. The switch should be carried out without undue delay within the shortest possible period of time. The following requirements for carrier portability are made [18]:

(1) Users must have the option to buy a SIM-unlocked handset enabling the use of alternative SIM cards of different providers. This is a precondition for changing carriers for outgoing communications (voice, SMS, data services) in international roaming. The chosen FSP would provide the visiting customer with an identity in its network by means of a new SIM card.

(2) Temporary number portability is an essential precondition for competition in the international mobile communications market. It allows mobile service customers to receive incoming voice, SMS and data roaming services on a visited network under their home mobile number when switching to a different provider only for a limited period of time or only for roaming services.

(3) The DSP should not be regulatory enforced to carry out the incasso function for international roaming services because the FSP also has the possibility to handle the billing for his roaming services. The DSP however should be regulatory obliged to provide the relevant source data on the identity and creditworthiness of its home customers if the DSP is not handling the billing.

Knieps and Zenhäusern [18] suggest that the current price as well as decoupling regulations should be abandoned and that the European regulators should instead implement the concept of carrier portability. In addition, measures of consumer protection such as information policies to avoid bill shocks should be obligatory for all mobile operators. This approach tackles the discrimination between home and visiting customers. As soon as consumers are free to choose any contract for 
mobile communications originating or received in the visited country, they are no longer forced into contractual relations with the home carrier or alternative roaming providers.

A variation on this carrier portability is the new SIM technology released by Apple at the end of 2014 [19]-[20]. Customers can take out short-term data plans with different mobile phone providers when needed. It also allows travelers to use a local network for data connections without the need to obtain a new SIM card from a local provider. This application of carrier portability is one step closer to an entirely software-based SIM for any country, which would give customers huge freedom in choosing their mobile supplier and allow them to switch mobile networks on-the-fly.

\subsection{Strategies for big operators: cross-border competition and traffic steering}

As mentioned above, cross-country operators have huge advantages over national operators when it comes to roaming costs and fees. In order to keep wholesale costs under control, it is essential to direct roamers to preferred networks. By this steering of the customer's traffic to one of its subsidiaries that is operating in the travel destination, cross-country operators can internalize roaming costs. This type of cross-border competition results in more affordable access and panEuropean (cross-country) networks implying cost reductions for both network deployment and operating expenditures effectively benefiting from economies of scale, though this would not necessarily imply that a uniform tariff for all EU users should emerge in such a market, or that the Commission should impose such a price.

This method is already used today: over the last years, a significant increase in the amount of mergers in the mobile telecom market can be observed for example in Austria (Hutchinson/Orange), Ireland (Three/Telefonica), Belgium (Liberty Global/Base) and Germany (Telefonica/E-Plus).

Due to the boundaries set by spectrum auctions and the country-specific IMSI (International Mobile Subscriber Identity) codes, the European telecom sector remains heavily fragmented: access availability, quality and prices vary significantly across the continent with telecom markets defined by national borders. To stimulate cross-border competition, the Commission, the European Parliament and the Council of the EU could use their regulatory powers to make it relatively more attractive to operate cross-border networks instead of focusing on domestic markets [21]. A possible policy is introducing supra-national allocation of radio spectrum [22]. Now, the allocation in the EU is done by member states within a framework of international coordination and harmonization, designed to counter cross-border interference. Auctions in different countries are run at different times, each assignment procedure has its own participation cost, bidders that want to operate in multiple countries are likely to calculate their bids for individual lots and face the risk of paying too much in early auctions if they fail to secure complementing licenses in later auctions, etc. This not only hinders the creation of operators with a larger European footprint, but also has a negative effect on network coverage and penetration. To reduce costs for operators and incentivize the deployment of networks with a larger European footprint, there should be a move towards EU-level assignment of spectrum.

On the downside, important to be mentioned, stimulating this strategy gives large MNOs an advantage over smaller ones and may result in only large cross-country operators remaining, hence leading to less competition and higher prices for customers.

\subsection{Strategy for smaller operators: IMSI beyond national borders}

Recently, the Belgian and Luxembourg telecom regulators made it possible to combine a Luxembourg IMSI to a Belgian mobile number and the other way around [23]. This is an interesting strategy since IMSIs are normally bound by national borders. The agreement makes it possible for 
operators to offer their services to customers in both their own country of operation and the other country and using either a location-based or a uniform pricing. By signing bilateral agreements with operators from other countries for a kind of "usage-based network lease", domestic operators can provide their users a transparent experience and themselves be reduced of high wholesale fees.

This option - signing bilateral agreements based on pan-national IMSI - may be the only option for smaller operators to secure their business case against high roaming fees. The European Commission could stimulate this by setting a unified Mobile Country Code for the whole of Europe. Traditional operators however renounce this evolution as they fear the increase in competition and the loss of roaming revenues.

\section{Summary and conclusion}

This paper aimed at giving an overview of the roaming regulation process in Europe, looking both at the past and the future. Roaming in Europe has gone through multiple processes of regulation since 2007, first imposing wholesale and retail price caps for calls, then for SMS and finally for data. The next step is lowering roaming prices to the level of retail prices, which in other words will permit users to roam like at home. However, there are several aspects that the EC still has to clarify, especially for the operators, as there are doubts about how they are going to sustain this transition: while the fee end users pay for roaming will be reduced to zero, the fee a domestic mobile operator pays the foreign mobile will not. To prevent abuse and "permanent roaming", the EC might have to introduce Fair Use Limits. While the goal of RLAH is for end users 'to roam like at home', the goal is not to choose for the cheapest (foreign) mobile operator and thus constantly 'roam at home'.

As operators will see a decline in revenue, they will need to look for new possibilities to cover their costs. The impact for the customers of these approaches will strongly depend on how the providers cope with these regulations, increased (national) prices may prove to be the unwanted outcome as this will have a negative impact on the operator's customer base. Other approaches may include the further decrease of wholesale roaming prices or the implementation of the FULs.

The roaming regulations imposed by the EU will push operators to explore new opportunities in the so-called 'single European market'. Some may help customers to quickly switch between operators and pick a plan suited for their needs, whereas other strategies may help maximize profits or optimize costs for the operators.

The real impact of the latest roaming initiative of the EC, Roaming Like At Home, is hard to predict as the outcome will differ per operator and depend on a lot of factors: the geographic location, the number of countries in which the operator is active and whether the operator is a MNO or MVNO; an advantage for a larger operator can easily prove to be a disadvantage for a smaller one. There is no universal strategy applicable for every MNO because of their inherent diversity and, correlated, the various heterogeneous markets in which they are active. As long as significant structural differences between EU countries continue to exist, it will be hard to come up with a single ideal solution for uniform roaming tariffs in the entire EU.

\section{REFERENCES}

[1] Eurostat

European

tourism

statistics.

Retrieved

from http://ec.europa.eu/eurostat/web/tourism/data/database

[2] European Commission (2014) E-Communications household survey and Telecom Single Market survey - Roaming results. Retrieved from https://ec.europa.eu/digital-agenda/en/news/ecommunications-household-survey-and-telecom-single-market-survey-roaming-results-special 
[3] European Commission (2014) Roaming: 300 million extra customers for telecoms companies when roaming charges end, survey shows. Retrieved from http://europa.eu/rapid/pressrelease_IP-14-152_en.htm

[4] European Commission. (2012) Regulation (EC) No 531/2012 Of the European Parliament and of the Council of 13 June 2012 on roaming on public mobile communications networks within the Union. June 2009. Retrieved from http://eur-lex.europa.eu/LexUriServ/LexUriServ.do?uri= OJ:L:2012:172:0010:0035:EN:PDF

[5] Infante, J., \& Vallejo, I. (2012) Regulation of international roaming in the European UnionLessons learned. Telecommunications Policy, 36(9), 736-748.

[6] Falch, M., \& Tadayoni, R. (2014) Regulation of international roaming data services within the EU. International Economics and Economic Policy, 11(1-2), 81-95.

[7] Scaramuzzi, E. (2009) European Roaming Regulation: Overview and Impact Assessment. Retrieved from http://www.cullen-international.com

[8] BEREC (2010) International Mobile Roaming Regulation. Retrieved from http://berec.europa.eu/doc/berec/bor_10_58.pdf

[9] European Commission (2013) Commission proposes major step forward for telecoms single market. Retrieved from http://europa.eu/rapid/press-release_IP-13-828_en.htm

[10] European Commission (2014) European Parliament votes to end roaming charges, expand consumer rights and make it easier to create better telecoms. Retrieved from http://europa.eu/rapid/press-release_IP-14-373_en.htm

[11] European Commission (2015) Commission welcomes agreement to end roaming charges and to guarantee an open Internet. Retrieved from http://europa.eu/rapid/press-release_IP-155265_en.htm

[12] Commission prepares the ground for the end of roaming charges in June 2017 Retrieved from http://ec.europa.eu/newsroom/dae/document.cfm?doc_id=16211

[13] BEREC (2014) International Roaming: Analysis of the impacts of "Roam Like at Home" (RLAH). Retrieved from http://berec.europa.eu/eng/document_register/subject_matter/berec/opinions/4826international-roaming-analysis-of-the-impacts-of-8220roam-like-at-home8221-rlah

[14] European Parliament - Parliamentary questions (2015) Answer given by Mr Oettinger on behalf of the Commission. Retrieved from http://www.europarl.europa.eu/sides/getAllAnswers.do?reference=E-2015011424 \&language $=E N$

[15] Explore EU country presence of operator groups. Retrieved from http://dfmonitor.eu/operators/

[16] MVNO Europe (2015) MVNO Europe is committed to the effective end of roaming charges. Retrieved from http://mvnoeurope.eu/mvnos-committed-to-effective-end-roaming-charges

[17] Summary report on the public consultation on the review of national wholesale roaming markets, fair use policy and the sustainability mechanism. Retrieved from https://ec.europa.eu/digital-single-market/en/news/summary-report-public-consultationreview-national-wholesale-roaming-markets-fair-use-policy

[18] Knieps, G., \& Zenhäusern, P. (2014) Regulatory fallacies in global telecommunications: the case of international mobile roaming. International Economics and Economic Policy, 11(1-2), 63-79.

[19]Gibbs, S. (2014, October 16) Apple iPad Air 2 brings soft sim to break mobile networks' stranglehold. Retrieved from https://www.theguardian.com/technology/2014/oct/16/appleipad-air-2-brings-soft-sim-to-break-mobile-networks-stranglehold

[20]Apple. Apple SIM. More choices for staying connected. Retrieved from https://www.apple.com/ipad/apple-sim/ 
[21] Aghion, P., Bloom, N., Blundell, R., Griffith, R. \& Howitt, P. (2005) Competition and Innovation: an Inverted-U Relationship, The Quarterly Journal of Economics, 120(2): 701-728

[22] Mariniello, M., \& Salemi, F. (2015) Addressing fragmentation in EU mobile telecom markets. Bruegel Policy Contribution ISSUE 2015/13, July 2015.

[23] BIPT (2015). Bilateral agreement between Belgian and Luxembourg telecoms regulators clears the way for calling, sending SMS messages and surfing between both countries without roaming costs. Retrieved from http://www.bipt.be/public/pressrelease/en/95/EN_Persbericht_BIPTILR.pdf 